\title{
Erratum to: Effects of calmodulin on expression of lignin-modifying enzymes in Pleurotus ostreatus
}

Takashi Suetomi · Takaiku Sakamoto • Yoshitaka Tokunaga • Toru Kameyama • Yoichi Honda • Hisatoshi Kamitsuji • Isamu Kameshita • Kousuke Izumitsu • Kazumi Suzuki · Toshikazu Irie

Published online: 9 January 2015

(C) Springer-Verlag Berlin Heidelberg 2015

\section{Erratum to: Curr Genet}

DOI 10.1007/s00294-014-0460-z

The original publication of this article unfortunately contained an error in Fig. 9. The scale of y-axis of the graphs in Fig. 9 must be reduced to about one-half or one-fifth of their present values. Corrected Fig. 9 is given below.

The online version of the original article can be found under doi:10.1007/s00294-014-0460-z.

T. Suetomi $\cdot$ T. Sakamoto $\cdot$ Y. Tokunaga $\cdot$ T. Kameyama

K. Izumitsu $\cdot$ K. Suzuki $\cdot$ T. Irie $(\triangle)$

School of Environmental Science, University of Shiga Prefecture,

2500 Hassaka-cho, Hikone, Shiga 522-8533, Japan

e-mail: tirie@ses.usp.ac.jp

Y. Honda

Graduate School of Agriculture, Kyoto University,

Kitashirakawa Oiwake-cho, Sakyo-ku, Kyoto 606-8502, Japan

H. Kamitsuji

Gifu Prefectural Research Institute for Forests,

1128-1 Sodai, Mino, Gifu 501-3714, Japan

I. Kameshita

Faculty of Agriculture, Kagawa University,

2393 Ikenobe, Miki, Kagawa 761-0795, Japan 

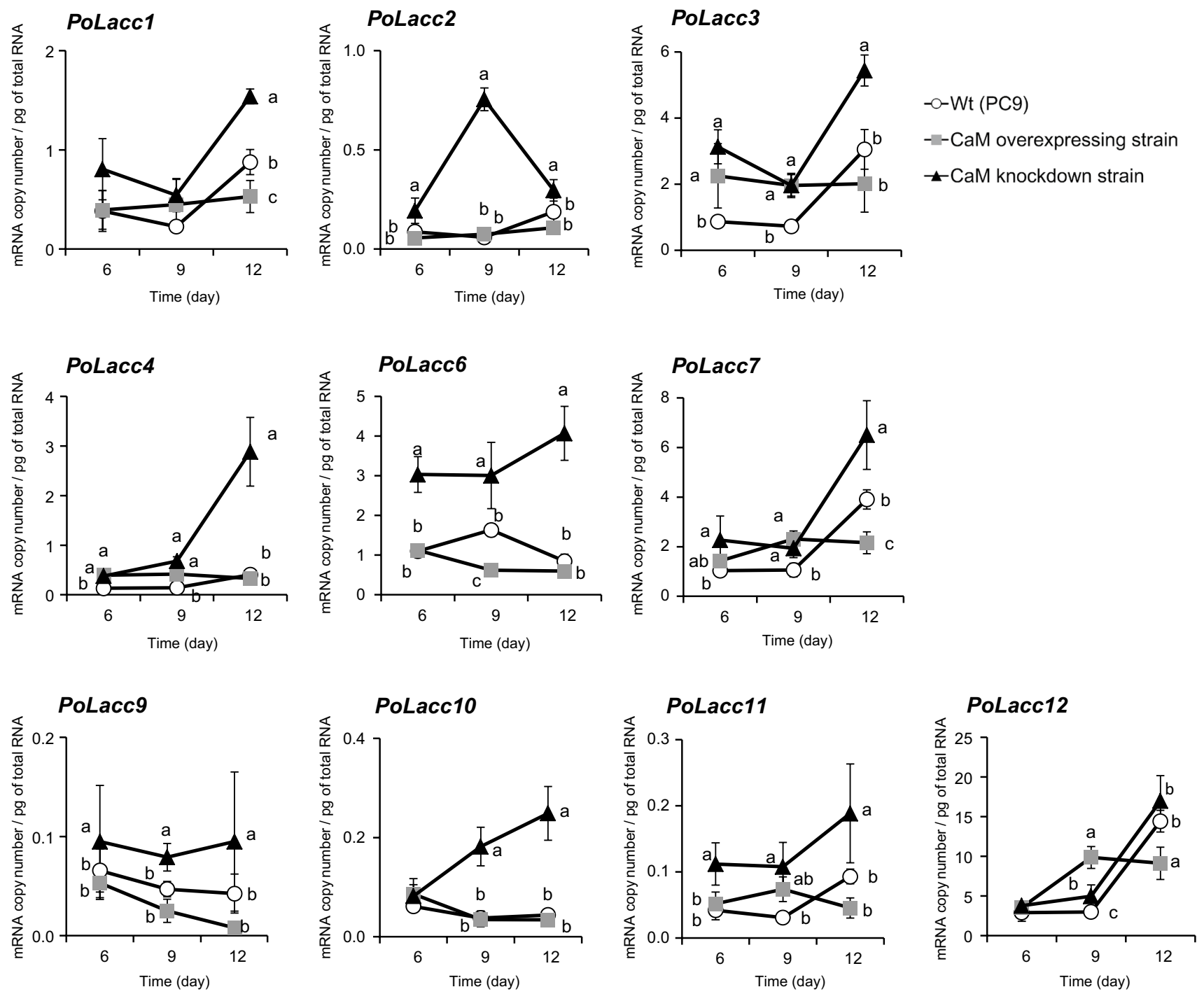

Fig. 9 Time courses of absolute Lac isozyme gene transcript levels. The mycelia were cultured in GP liquid medium containing $0.27 \mathrm{mM}$ $\mathrm{MnSO}_{4}$. The culture filtrates were used for enzyme assay. Total RNA was extracted from the mycelia and used to measure isozyme gene

transcript levels with real-time RT-PCR. The experiment was repeated four times. Error bars indicate mean \pm SD for four biological repetitions. Mean values not sharing a common letter are significantly different among strains $(P<0.05)$ 